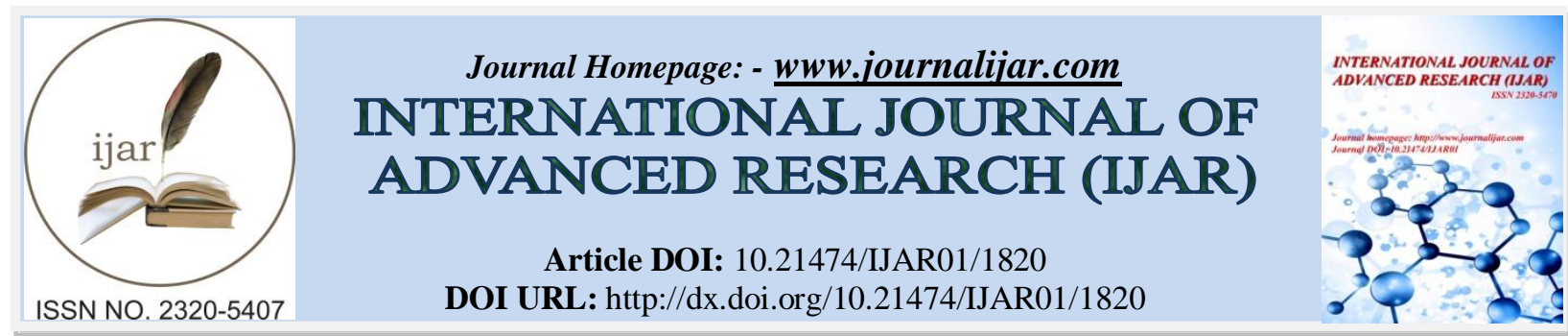

RESEARCH ARTICLE

\title{
A COMPARATIVE STUDY FOR THE REMOVAL OF COPPER AND ZINC IONS USING SOME TREATED CARBON
}

R. S. Salama, H. A. Kiwaan and M. R. Mostafa.

Department of Chemistry, Faculty of Science, Damietta University

\section{Manuscript Info}

Manuscript History

Received: 10 August 2016

Final Accepted: 23 September 2016

Published: October 2016

Key words:-

Chemically activated carbon, Heavy

metal removal, Adsorption properties.

\section{Abstract}

The objective of this study is to assess the uptake of copper and zinc ions from their aqueous solutions onto activated carbons obtained from date stone by chemical activated method using $\mathrm{H}_{3} \mathrm{PO}_{4}$ and $\mathrm{ZnCl}_{2}$. The comparison with a commercial activated carbon has been made. The influence of loading of commercial activated carbon with $10 \mathrm{wt}$. $\%$ hydrous zirconium oxide on the textural and adsorptive properties was also studied. The characterization of prepared carbons is performed by scanning electron microscopy (SEM), Fourier transform infrared spectroscopy (FTIR) and nitrogen adsorption at 77K. FTIR reveals the presence of different oxygen-containing functional groups on the surface of phosphoric acid and zinc chloride activated carbons. Adsorption isotherms of $\mathrm{Cu}$ (II) and $\mathrm{Zn}$ (II) onto investigated carbons were determined by batch experiments.

Langmuir model is well studied to fit the adsorption isotherm data. Loading of commercial activated carbon with $10 \mathrm{wt}$ \% hydrous zirconium oxide decrease the surface area and the porosity of the sample and increase to a great extent its adsorption capacity for the removal of $\mathrm{Cu}$ (II) and $\mathrm{Zn}$ (II). The surface chemical nature of activated carbons seems to be the most important factor in this adsorption process.

The thermodynamic parameters $\Delta \mathrm{H}^{0}, \Delta \mathrm{S}^{0}, \Delta \mathrm{G}^{0}$ related to the adsorption process for the two metal ions on OC and OCZ carbons were determined.

Copy Right, IJAR, 2016,. All rights reserved.

\section{Introduction:-}

Over the past few decades the huge increase in the use of heavy metals has resulted in an increased flux of metallic substances in aquatic environment. The discharge of these toxic metals into water causes a serious pollution problem which may affect the quality of water supply. The most important characteristics of these metals are that they are non-degradable and therefore persistent [1]. Furthermore, most of heavy metals ions are toxic to living organisms [2]. Due to their threat to human life and the environment, the intensive disposal of these toxic substances without control constitutes a real danger. Therefore, a considerable effort has been dedicated in the past years concerning the removal of these metals from wastewater to a limit approaching those of drinking water standards [3] before its disposal. 
Different industries such as electro-plating, zinc base casting, brass manufacture, mining pigments, and other industries discharge significant amount of copper and zinc in various forms to the environments. The toxicity of the two metal ions to humans and the environments is well known and high concentration for each metal ion causes lungs and bone cancers [4]. Hence the recovery of the two metal ions from water and wastewater assumes importance. Several methods are commonly used for this purpose including chemical precipitation, ion exchange, membrane filtration, electro dialysis and liquid extraction [5, 6]. However, there are some specific disadvantages using most of these methods including costly equipment and operation, energy and space requirements and low feasibility for small scale industries [7]. Adsorption is also an attractive option for the removal of heavy metals from their aqueous solutions. The most common adsorbent materials are metal oxides [8,9], polymers [10, 11] and activated carbon [12-16]. To the present, activated carbon remains to be one of the most important micro-porous adsorbent from an industrial view of point. Nowadays, activated carbon can be produced from a large number of abundant and low cost materials from agriculture waste such as coconut coir pith [17], sawdust [18], rice husk [19], banana pith [20], sugarcane bagasse pith [21] and peanut hull [22] which they possesses a high carbon and a low inorganic content.

Annually, Egypt consumes an average of three hundred thousand tons of dates, all these quantities of dates end up in the form of date stones in the discharges. Hence, the interest is to recover and to develop this waste material by converting it to activated carbon for need to the water treatment processes. In this context, the present paper aims to compare the adsorption capacities of four activated carbons for the removal of copper and zinc ions from their aqueous solutions. Two of activated carbons were derived from date stones by activated with $\mathrm{ZnCl}_{2}$ and $\mathrm{H}_{3} \mathrm{PO}_{4}$ agents. The other two carbons, one of them is a commercial product obtained from (RUTGERS CarboTech) which is essentially used for removing residual free chlorine from water. The other is the commercial carbon loaded with $10 \%$ hydrous zirconium oxide in a trail to improve its adsorption capacity towards the two metal ions. The thermodynamic parameters $\left(\Delta \mathrm{H}^{0}, \Delta \mathrm{S}^{0}, \Delta \mathrm{G}^{0}\right)$ are evaluated and discussed.

\section{Materials and carbon characterization:- Materials:-}

Date stones were obtained from the pastry date manufacturing in Egypt. Firstly the date stones was washed with 10 $\% \mathrm{HCl}$, tap water and finally with distilled water and then dried at $110 \mathrm{C}^{0}$ for about 48 hours. The clean stones were carbonized in a horizontal stainless cylindrical reactor ( length of $600 \mathrm{~mm}$ and internal diameter $40 \mathrm{~mm}$ ) heated by a $500 \mathrm{~mm}$ long electrical oven. The chemical activation method using $\mathrm{H}_{3} \mathrm{PO}_{4}$ or $\mathrm{ZnCl}_{2}$ agent requires two successive steps: the date stones firstly were slowly charred under a nitrogen flow $(50 \mathrm{ml} / \mathrm{min}$. $)$ at $350 \mathrm{C}^{0}$ for 2 hours. A part of charred material is soaked in $\mathrm{H}_{3} \mathrm{PO}_{4}$ until impregnation ratio of $0.75 \mathrm{~g} \mathrm{of}_{3} \mathrm{PO}_{4} / 1 \mathrm{~g}$ of initial char is reached while the second part is soaked in $\mathrm{ZnCl}_{2}$ with the same impregnation ratio. The oven dried impregnated products is then heated in nitrogen atmosphere at $550 \mathrm{C}^{0}$ for 4 hours. The resulting materials are repeatedly washed with hot water until $\mathrm{pH}$ of the washed solution was near to $6.5 \pm 0.1$. The products obtained were dried at $110 \mathrm{C}^{0}$ to a constant weight and were then stored in a well closed bottles. Phosphoric acid and zinc chloride activated carbons produced by this method are designated PC and ZC respectively. The commercial activated carbon used in the present study is designated as OC and used without any treatment. 10 weight $\%$ hydrous zirconium oxide was loaded to the $110 \mathrm{C}^{0}$ dried OC sample as follows: the carbon sample was suspended in a $100 \mathrm{ml}$ of $0.5 \mathrm{~N}$ HCL solution containing appropriate amount of $\mathrm{ZrOCl}_{2} \cdot 8 \mathrm{H}_{2} \mathrm{O}$. An aqueous solution of $10 \% \mathrm{NH}_{4} \mathrm{OH}$ was added drop by drop to the previous solution with vigorous stirring until $\mathrm{pH}=9$. The resulting material was separated by filtration, washed for several times with $2 \% \mathrm{NH}_{4} \mathrm{Cl}$ solution and then with hot distilled water till free from chloride ion and dried at 110 $\mathrm{C}^{0}$ for 24 hours. This sample was referred to as OCZ.

\section{Carbon characterizations:-}

The surface morphology of investigated carbons was observed by coating the sample with gold using scanning electron microscopy SEM (JSM-6510LV). The textural properties of activated carbon were determined from the adsorption of nitrogen at 77K using an automatic sorption apparatus (Quanta Chrome model Nova 3200). The data obtained from nitrogen adsorption-desorption isotherms were used to determine the following parameters: $S_{\mathrm{BET}}$ (Apparent surface area as calculated from the BET equation), $\mathrm{V}_{\mathrm{T}}$ (volume adsorbed at $\mathrm{p} / \mathrm{p}^{0}=0.95$, corresponds to the micro-pore + meso-pore volume), $\mathrm{V}_{\text {micro }}$ (volume adsorbed at $\mathrm{p} / \mathrm{p}^{0}=0.2$, indicates the total micro-porosity volume), $\mathrm{V}_{\text {meso }}$ (meso-pore volume as calculated from the difference between the volume adsorbed at $\mathrm{p} / \mathrm{p}^{0}$ of 0.95 and 0.2) and mean pore radius " $\vec{r}\left(A^{\circ}\right)$ " as calculated from the values of $S_{B E T}$ and $V_{T}$ (assuming a cylindrical pore model). The FTIR spectra of the samples were recorded between 4000 and $400 \mathrm{~cm}^{-1}$ using a Jasco infrared 
spectrometer model 410 . The samples were mixed with $\mathrm{KBr}$ and the mixture was pressed into pellets to be used in the analysis.

\section{Adsorption experiments:-}

The Adsorption tests are carried out in batch mode using $0.2 \mathrm{~g}$ of activated carbon. Stock solutions of $\mathrm{Cu}$ (II) and $\mathrm{Zn}$ (II) were prepared by dissolving reagent grade $\mathrm{CuCl}_{2} \cdot 2 \mathrm{H}_{2} \mathrm{O}$ and $\mathrm{ZnCl}_{2}$ in de-ionized water respectively. $50 \mathrm{ml}$ aqueous solutions of each metal ion bearing $0.2 \mathrm{~g}$ of activated carbon in $100 \mathrm{ml}$ stopper glass bottles were shaken for 24 hours at desired temperature. The initial concentrations of $\mathrm{Cu}$ (II) and $\mathrm{Zn}$ (II) in the solution were varied from 50 to $450 \mathrm{mg} / \mathrm{L}$. The $\mathrm{pH}$ of the solutions was always in the range 6.0 to 6.5 throughout the experiments to prevent precipitation of metal hydroxides [23, 24]. The concentration of each metal ion in the supernatant solution was measured by atomic adsorption spectrometer (Analyst model 400). The amount of $\mathrm{Cu}$ (II) and $\mathrm{Zn}$ (II) adsorbed on each carbon, $\mathrm{q}_{\mathrm{e}},(\mathrm{mg} / \mathrm{g})$ were calculated from the following relationship:

$$
\mathbf{q}_{\mathrm{e}}=\left(\mathrm{C}_{\mathrm{i}}-\mathrm{C}_{\mathrm{e}}\right) \mathrm{V} / \mathrm{m}
$$

Where $\mathrm{C}_{\mathrm{i}}, \mathrm{C}_{\mathrm{e}}$ are the initial and equilibrium concentrations of each metal ion $(\mathrm{mg} / \mathrm{l})$ respectively, $\mathrm{V}$, is the volume of the solution $(\mathrm{L})$ and $\mathrm{m}$ is the mass of carbon $(\mathrm{g})$.

\section{Results and Discussion:-}

Surface morphology of carbons:-

The SEM images of the prepared carbons are shown in Fig. 1. Fig1, a, b clearly illustrates the development of porosity upon activation with $\mathrm{ZnCl}_{2}$ and $\mathrm{H}_{3} \mathrm{PO}_{4}$. A comparison between the two images showed that activation with $\mathrm{H}_{3} \mathrm{PO}_{4}$ results in more homogeneous surface with large number of pores while sample $\mathrm{ZC}$ has a considerable number of disordered random of shallow cavities. These images also show the deposition of some inorganic species on each sample surface. Fig. 1, c, d shows SEM micrographs of commercial activated carbon "OC" and that after loading with 10 weight \% hydrous zirconium oxide "OCZ". In case of OC (c), the individual particles are fractallike shape and displayed various kinds of porosity, while the surface of OCZ sample (d), are pitted and fragmented with the presence of fine particles of hydrous zirconium oxide deposited on the surface.

(a)

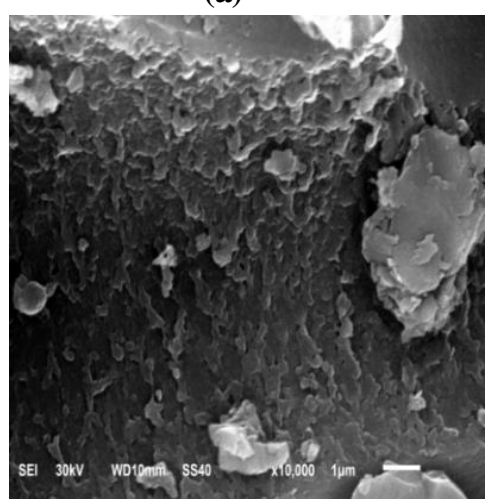

(c)

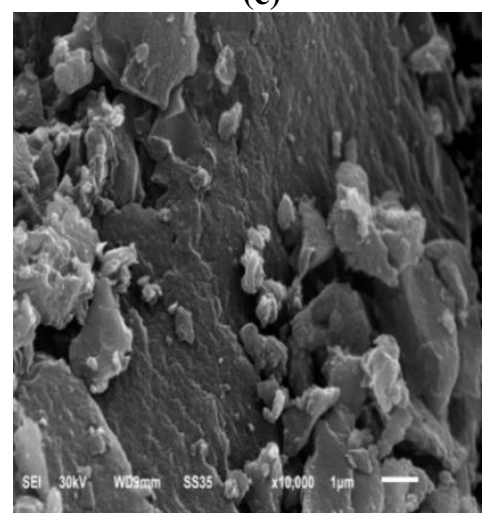

Fig.1:- SEM micrographs of (a) ZC, (b) PC, (c) OC and (d) OCZ carbons (b)

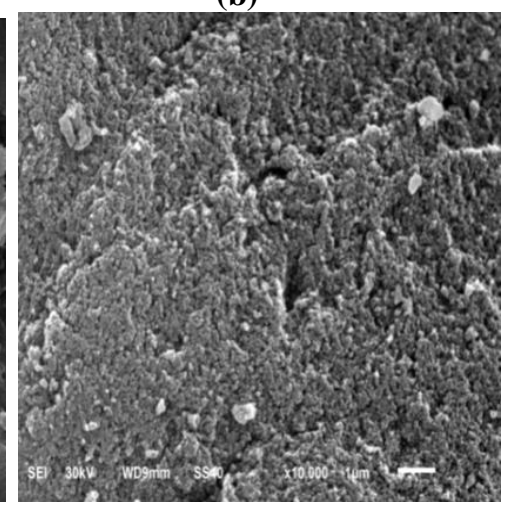

(d)

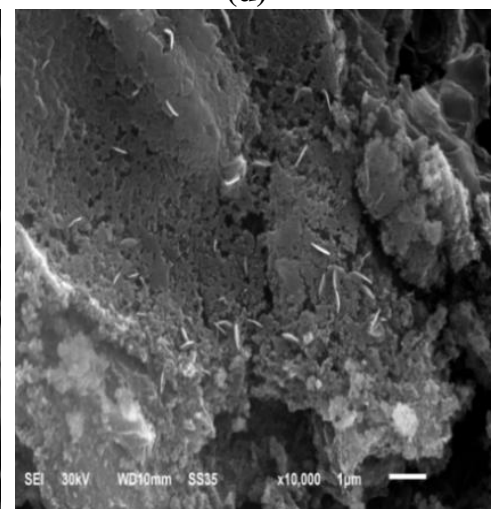




\section{Textural properties:}

Nitrogen adsorption-desorption isotherms at $77 \mathrm{~K}$ of the investigated carbons are shown in figure (2). As shown in this figure, the adsorption isotherm obtained for commercial activated carbon (OC) is clearly type I according to the IUPAC classification [25], showing a plateau and no hysteresis. Such as isotherm is typical of an internal structure mainly micro-porous with a narrow distribution of porous size. In contrast $\mathrm{ZnCl}_{2}$ and $\mathrm{H}_{3} \mathrm{PO}_{4}$ activated carbons as well as the sample loaded with 10 weight \% hydrous zirconium oxide (OCZ) exhibit isotherms of type I with hysteresis loop of $\mathrm{H}_{4}$ [25]. The type I isotherm character associated with $\mathrm{H}_{4}$ type indicative the high degree micro porosity. The appearance of hysteresis loops in the nitrogen isotherms of these carbons indicates the existence of some miso-porosity. The hysteresis loop of $\mathrm{H}_{4}$ is indicative of slit shaped pore, where the adsorption and desorption branches are parallel. Similar effects of the alkaline and acidic activating agents on the textural characteristics for different activated carbons have been observed by many of the previous worker [26-28]. The conventional BET equation [29] was applied over the relative pressure range $0.02 \leq \mathrm{P} / \mathrm{P}^{0} \leq 0.35$ (Fig.3) to determine the monolayer $\mathrm{V}_{\mathrm{m}}$ and hence the specific BET area $\left(\mathrm{S}_{\mathrm{BET}} \mathrm{m}^{2} / \mathrm{g}\right)$ by adopting the value of $0.16 \mathrm{~nm}^{2}$ for the cross-sectional area of nitrogen molecule at $77 \mathrm{~K}$.

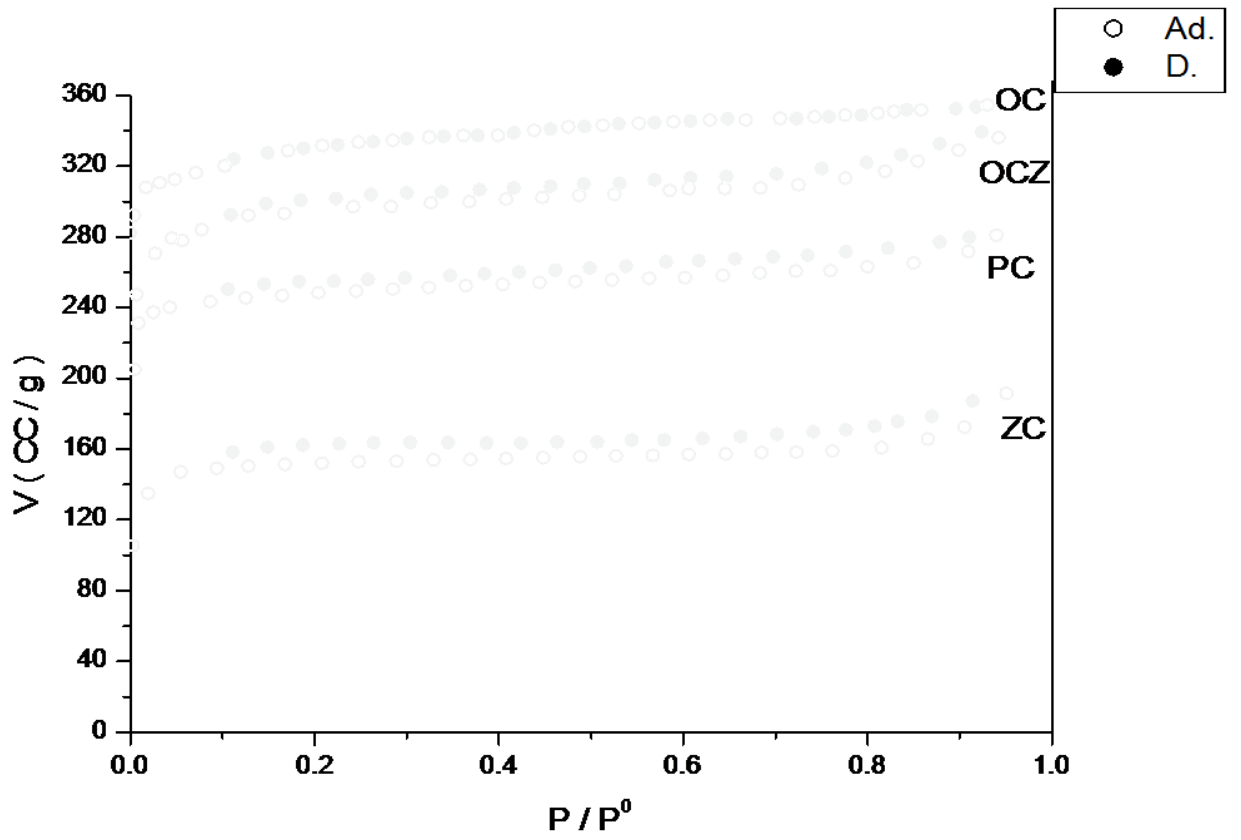

Fig.2:- Nitrogen adsorption-desorption isotherms at 77K of ZC, PC, OC and OCZ carbons. 


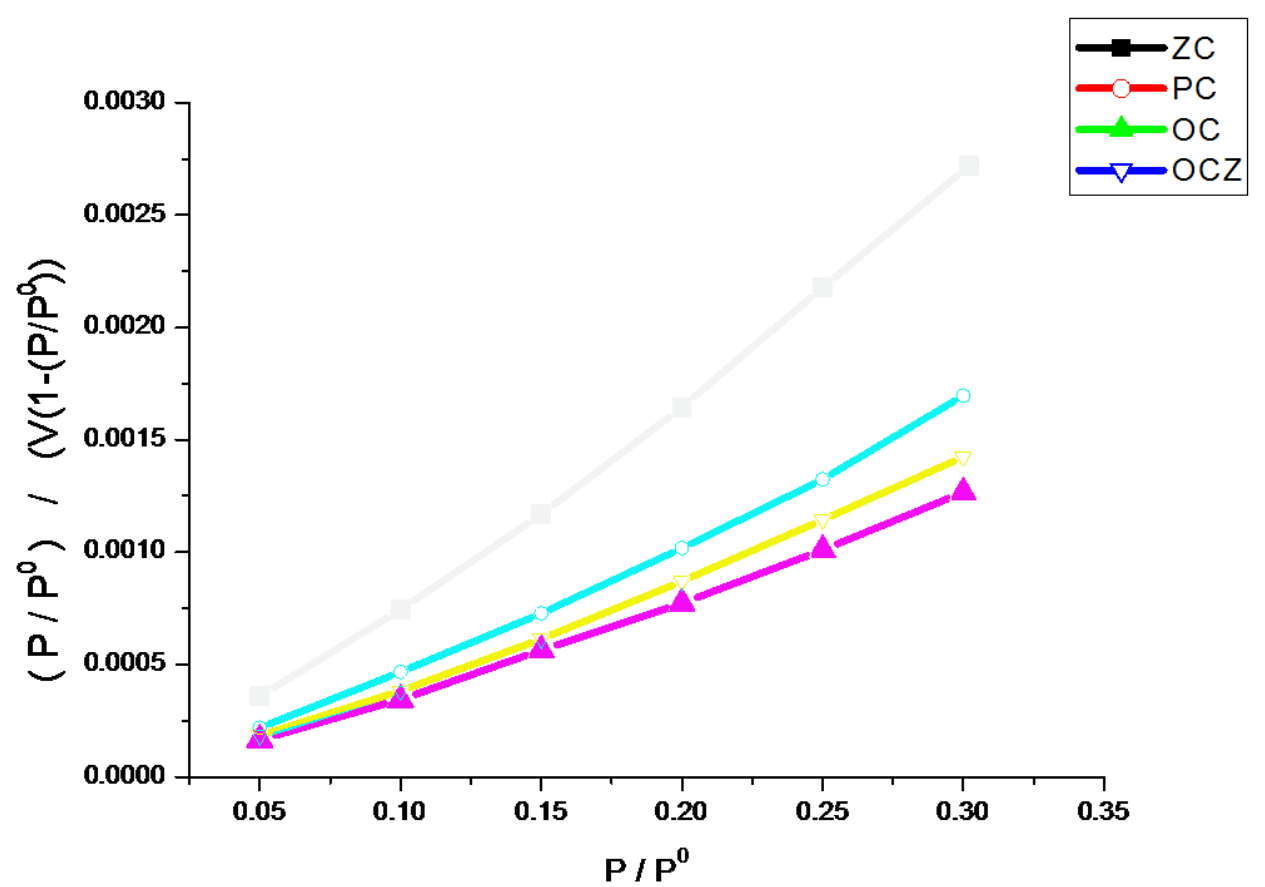

Fig 3:- BET plots for nitrogen adsorption isotherm for $\mathrm{ZC}, \mathrm{PC}, \mathrm{OC}$ and $\mathrm{OCZ}$ carbons.

Table (1) summarizes the textural parameters of the investigated carbons as derived from the adsorption isotherms and BET equation as well as from $\alpha_{s}$ plots (not illustrated) [30]. It is evident from table (1) that comparable areas and total pore volumes for each carbon sample are obtained using BET equation and $\alpha_{\mathrm{s}}$ method. Table (1) reveals also that the commercial carbon (OC) measured the highest $S_{\mathrm{BET}}$ and $\mathrm{V}_{\mathrm{T}}$ values while the carbon obtained from $\mathrm{ZnCl}_{2}$ activation (ZC) measured the lowest $\mathrm{S}_{\mathrm{BET}}$ and $\mathrm{V}_{\mathrm{T}}$ values. Loading of "OC" sample with 10 weight \% of hydrous zirconium oxide led to decrease both of $\mathrm{S}_{\mathrm{BET}}$ and $\mathrm{V}_{\mathrm{T}}$ values which may be due to the partial blocking of the developed pores by zirconium oxide particles causing thus decrease of both $\mathrm{S}_{\mathrm{BET}}$ and $\mathrm{V}_{\mathrm{T}}$. Table (1) reveals also that for all sample $85 \%$ of the pore volume is filled below $\mathrm{P} / \mathrm{P}^{0}=0.2$, indicate the prepared carbons are highly micro porous. After the sharp movements up to $\mathrm{P} / \mathrm{P}^{0}$ of 0.2 , the isotherm slowly bends showing smaller increment in adsorption process.

Table.1:- Textural parameters of the investigated carbons.

\begin{tabular}{|c|c|c|c|c|c|c|c|c|}
\hline Sample & $\begin{array}{c}\mathbf{S}_{\text {BET }} \\
\left(\mathrm{m}^{2} / \mathrm{g}\right)\end{array}$ & $\begin{array}{c}\mathbf{V}_{\mathbf{T}} \\
(\mathrm{ml} / \mathrm{g})\end{array}$ & $\begin{array}{c}\mathbf{V}_{\text {micro }} \\
(\mathrm{ml} / \mathrm{g})\end{array}$ & $\begin{array}{c}\mathbf{V}_{\text {meso }} \\
(\mathrm{ml} / \mathrm{g})\end{array}$ & $\begin{array}{c}\mathbf{r}^{-} \\
(\AA)\end{array}$ & $\begin{array}{c}\mathbf{S}^{\alpha} \\
\left(\mathrm{m}^{2} / \mathrm{g}\right)\end{array}$ & $\begin{array}{c}\mathbf{V}^{\boldsymbol{\alpha}}{ }_{\text {micro }} \\
(\mathrm{ml} / \mathrm{g})\end{array}$ & $\begin{array}{c}\mathbf{S}^{\boldsymbol{\alpha}}{ }_{\mathbf{n}} \\
\left(\mathrm{m}^{2} / \mathrm{g}\right)\end{array}$ \\
\hline $\mathbf{Z C}$ & 500 & 0.28 & 0.22 & 0.06 & 10.8 & 486 & 0.22 & 38 \\
\hline $\mathbf{P C}$ & 728 & 0.42 & 0.38 & 0.04 & 12.5 & 718 & 0.36 & 46 \\
\hline $\mathbf{O C}$ & 959 & 0.55 & 0.51 & 0.04 & 11.8 & 926 & 0.51 & -- \\
\hline $\mathbf{O C Z}$ & 840 & 0.49 & 0.42 & 0.07 & 11.5 & 800 & 0.40 & 64 \\
\hline
\end{tabular}

\section{FTIR studies:-}

The assignment of absorption bands in the FTIR spectrum of natural date stones (not illustrated) shows that the functional groups, alkene, ester, aromatic, ketone, hydroxyl, ether and carboxylic are present in the material. This is in accordance with the composition of date pets, which are essentially composed of cellulose, hemicelluloses and lignin [31]. Fig.4. shows the FTIR spectrum of the carbons under investigation. PC and ZC carbons showed broad band's at 3380-3420 $\mathrm{cm}^{-1}$ which may be due to hydrogen bonded of $\mathrm{OH}$ stretching vibration that arise probably from the interaction between adsorbed water molecules from environment and $\mathrm{OH}$ groups on the carbon surface[32]. For the carbon obtained by activation with $\mathrm{H}_{3} \mathrm{PO}_{4}$ (Fig.4a) the bands found at 1690 and $1586 \mathrm{~cm}^{-1}$ are assigned to the presence of $\mathrm{C}=\mathrm{O}$ stretching vibrations in ketones and carboxylic acids and $\mathrm{C}=\mathrm{C}$ stretching vibration in olefinic double bonds respectively [33]. In addition the more developed bands at 1436, 1160,980 and $490 \mathrm{~cm}^{-1}$ (Fig.4a) may be ascribed to $\mathrm{R}$-aryl $\mathrm{P}-\mathrm{O}-\mathrm{C}$ stretching in phosphate groups and $\mathrm{P}=\mathrm{O}$ respectively [34]. The appearance of phosphate bands suggest that the presence of phosphate residues in the carbon matrix even after intensive and 
repeated washings. On the other hand the FTIR spectrum of ZC carbon (Fig.4b) displays a number of stronger bands or shoulders at 1700,1600 and $1230-1140 \mathrm{~cm}^{-1}$ which are assigned to the presence of $\mathrm{C}=\mathrm{O}$ (in carboxylic, lactonic and ketone), $\mathrm{C}=\mathrm{C}$ ( in olefinic, double bonds) and $\mathrm{C}-\mathrm{OH}$ (in phenols) function groups. In addition a weak $\mathrm{Zn}-\mathrm{O}$ band at $430 \mathrm{~cm}^{-1}$ was also located in ZC spectrum [35].

The FTIR spectrum of OC, "commercial activated carbon" is shown in Fig. 4c. Broad band located at 3150-3500 $\mathrm{cm}^{-1}$ which is attributed to the stretching modes of $\mathrm{OH}$ band related to free water (physisorbed water). The weak band located at $1720 \mathrm{~cm}^{-1}$ is usually caused by stretching vibration of $\mathrm{C}=\mathrm{O}$ in ketones, aldehydes and carboxyl groups, while the band around $1425 \mathrm{~cm}^{-1}$ is assigned to scissoring vibration of ( $\left.-\mathrm{CH}_{2}\right)$ group or to in-plane of $\mathrm{H}-$ bonded hydroxyl group. The band around $1091 \mathrm{~cm}^{-1}$ assigned to in-plane bending of aromatic ring $\mathrm{C}-\mathrm{H}$ bond while that at $874 \mathrm{~cm}^{-1}$ is scribed to out of plane of alkene $(=\mathrm{C}-\mathrm{H})$ bending or out of plane bending of ring $\mathrm{C}-\mathrm{H}$ bond [36]. On the contrary, the spectrum of OCZ carbons Fig.4d shows a more developed and broad band at $3100-3450 \mathrm{~cm}^{-1}$ and weak one located at $1600 \mathrm{~cm}^{-1}$. The former was assigned to the stretching modes of $\mathrm{OH}$ related to surface adsorbed water and the latter were due to the bending mode of H-O-H band [37]. In addition the spectrum of OCZ carbon shows two bands at 1384 and $1563 \mathrm{~cm}^{-1}$. The band located at $1384 \mathrm{~cm}^{-1}$ was assigned to bending vibration of $\mathrm{Zr}-\mathrm{OH}$ groups, while that located at $1563 \mathrm{~cm}^{-1}$ was assigned to $\mathrm{Zr}-\mathrm{OH}$ vibration $[38,39]$.

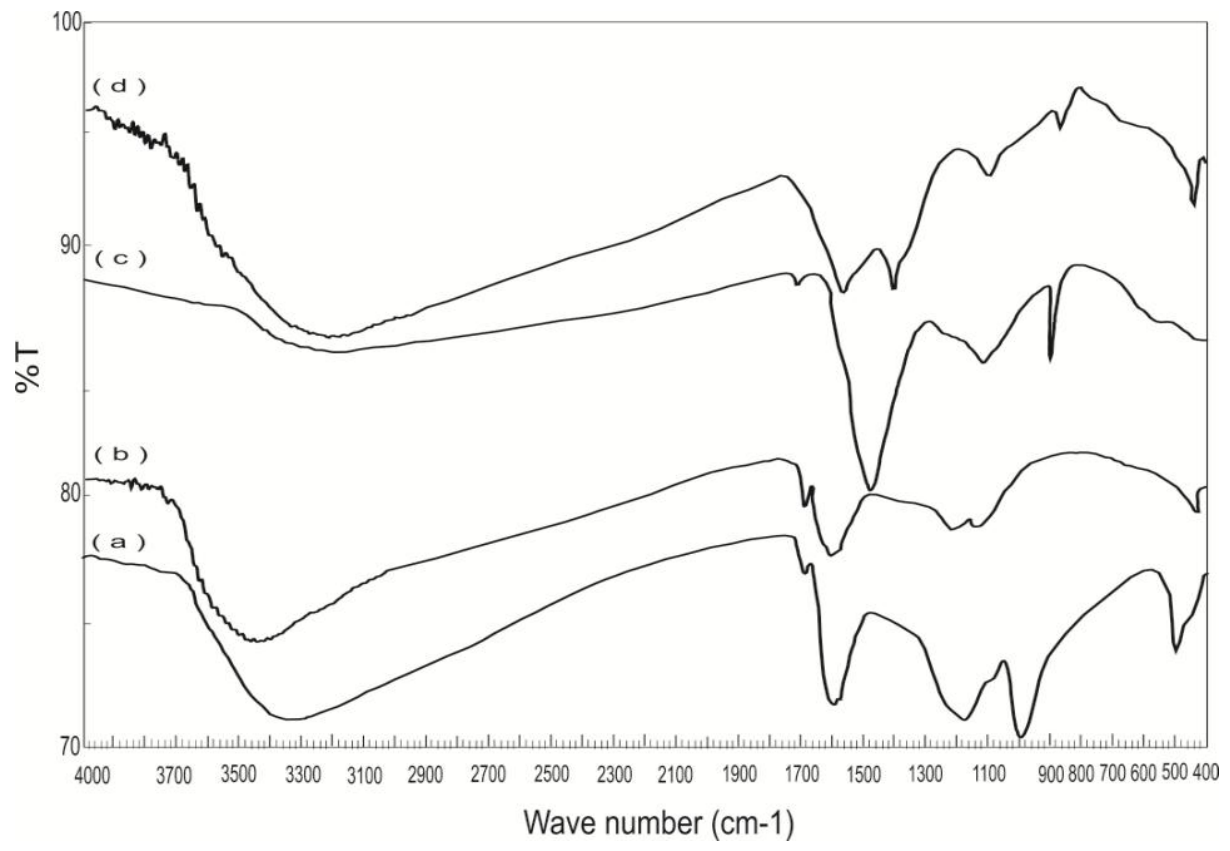

Fig.4:- FTIR spectra of (a) PC, (b) ZC, (c) OC and (d) OCZ carbons.

\section{Adsorption isotherms:-}

The adsorption of $\mathrm{Cu}$ (II) and $\mathrm{Zn}$ (II) on the investigated carbons exhibit adsorption isotherms typical to those characterizing adsorption from solution. In the initial portion of the isotherm, the amount of metal ion uptake increase considerably with the increase of concentration. At intermediate concentrations a tendency to reach a maximum adsorption value is shown. Fig.5 shows the adsorption isotherms of $\mathrm{Cu}$ (II) and $\mathrm{Zn}$ (II) on some selected carbons. Several models have been published in the literature to analysis the isotherm data. In the present study the sorption data was analyzed in term of Langmuir model [40]. The model assumes uniform energy of adsorption onto the surface and the uptake occurs on homogeneous surface by monolayer of one molecule thick without interaction between sorbed molecules. The liner form of Langmuir isotherm is represented by the following equation:

$$
\frac{\mathrm{C}_{\mathrm{e}}}{\mathrm{q}_{\mathrm{e}}}=\frac{1}{\mathrm{bQ}_{\mathrm{o}}}+\frac{\mathrm{C}_{\mathrm{e}}}{\mathrm{Q}_{\mathrm{o}}} .
$$

Where $\mathrm{C}_{\mathrm{e}}$ is the equilibrium metal ion concentration $(\mathrm{mg} / \mathrm{l}), \mathrm{q}_{\mathrm{e}}$ the amount of copper or zinc ions adsorbed at equilibrium $(\mathrm{mg} / \mathrm{g}), \mathrm{Q}_{0}(\mathrm{mg} / \mathrm{g})$ and $\mathrm{b}(\mathrm{L} / \mathrm{mg})$ are Langmuir constants related to monolayer capacity and energy of adsorption respectively. Fig.6 shows the linear Langmuir plots for some representative samples. The Langmuir constants $\mathrm{Q}_{\mathrm{m}}$ and $\mathrm{b}$ were calculated from these plots and are listed in Table2. 
A characteristic of Langmuir isotherm is the definition of a dimensionless factor $\mathrm{R}_{\mathrm{L}}$ [41] defined as:

$$
\mathrm{R}_{\mathrm{L}}=\frac{1}{1+\mathrm{bC}_{\mathrm{o}}}
$$

Where, $\mathrm{C}_{0}$ is the initial concentration of each metal ion. Thus, $\mathrm{R}_{\mathrm{L}}$ is a positive number whose magnitude determines the feasibility of the sorption process. The process is irreversible if $\mathrm{R}_{\mathrm{L}}=0$, Favourable if $0<\mathrm{R}_{\mathrm{L}}<1$, Liner if $\mathrm{R}_{\mathrm{L}}=1$ and unfavorable if $R_{L}>1$. $R_{L}$ values between 0 and 1 (Table 2) were obtained indicating thus the adsorption of both metal ion on the tested carbons seems to be favorable.

Comparing the monolayer capacities $\left(\mathrm{Q}_{0}\right.$ values) of the investigated carbons toward the adsorption of both $\mathrm{Cu}$ (II) and $\mathrm{Zn}$ (II) indicates that, commercial activated carbon (OC) measure lowest $\mathrm{Q}_{0}$ values for both metal ions although it has the highest $\mathrm{S}_{\mathrm{BET}}$ area (CF. Table 1). This indicates that the extent of surface is not the only factor which determines the adsorption of two metal ions on the tested carbons. Further evidence that the uptake of the two metal ions does not depend only on the extent of the surface is indicated by the highest values of $\mathrm{Q}_{0}$ for the two metal ions measured by OCZ carbon which measure relatively low $\mathrm{S}_{\mathrm{BET}}$ area than OC carbon. It seems that the hydroxyl groups that may rest on the carbon surface as a result of loading hydrous zirconium oxide on OC carbon may act as additional active centers capable to sequestrate the two metal ions from their aqueous solutions. Intermediate monolayer capacities are obtained by ZC and PC carbons. The two carbons are characterized by the presence of acidic functional group as indicated from their FTIR spectra. The fact that PC carbon measures higher uptake values for $\mathrm{Cu}$ (II) and $\mathrm{Zn}$ (II) than those obtained by ZC carbon may be due to the presence of some phosphate groups that may act as active centers contribute in $\mathrm{Cu}$ (II) and $\mathrm{Zn}$ (II) sequestration. This may be taken as additional evidence that the surface chemical nature of the prepared carbons plays the major roles to inflict the highest impact on $\mathrm{Cu}$ (II) and $\mathrm{Zn}$ (II) ions removal. Table (2) indicates also that $\mathrm{Cu}$ (II) is removed in somewhat higher amount than $\mathrm{Zn}$ (II) on all carbons.

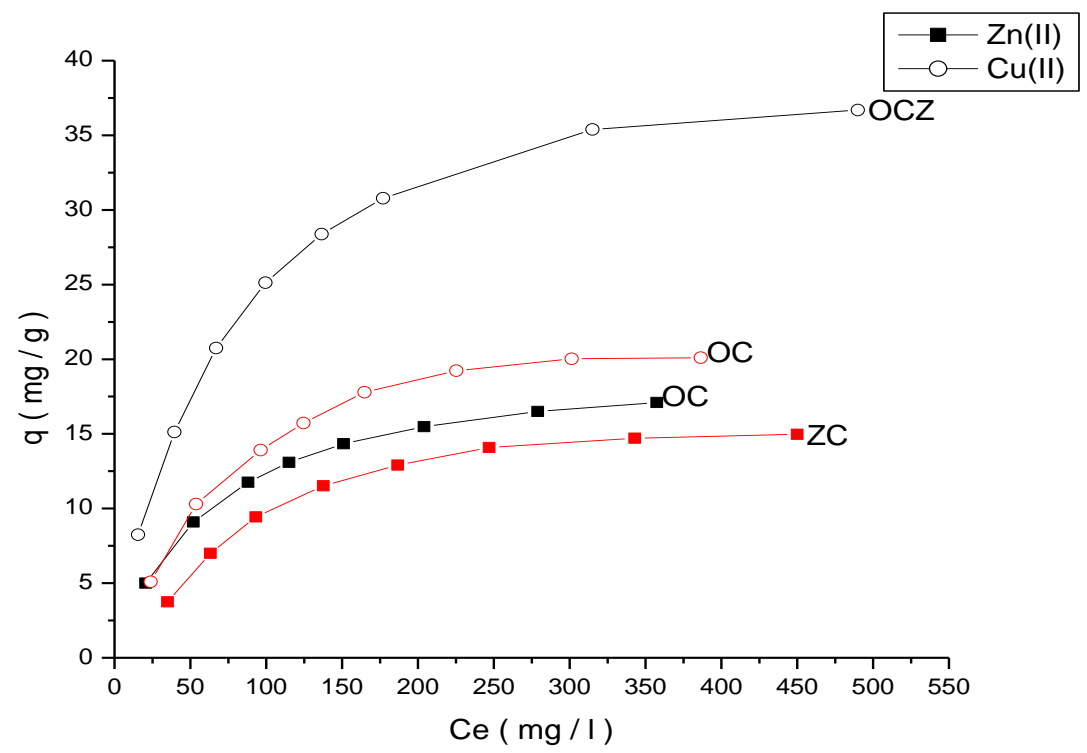

Fig.5:- Adsorption isotherms of $\mathrm{Cu}$ (II) and $\mathrm{Zn}$ (II) ions on some selected carbons at 298K. 


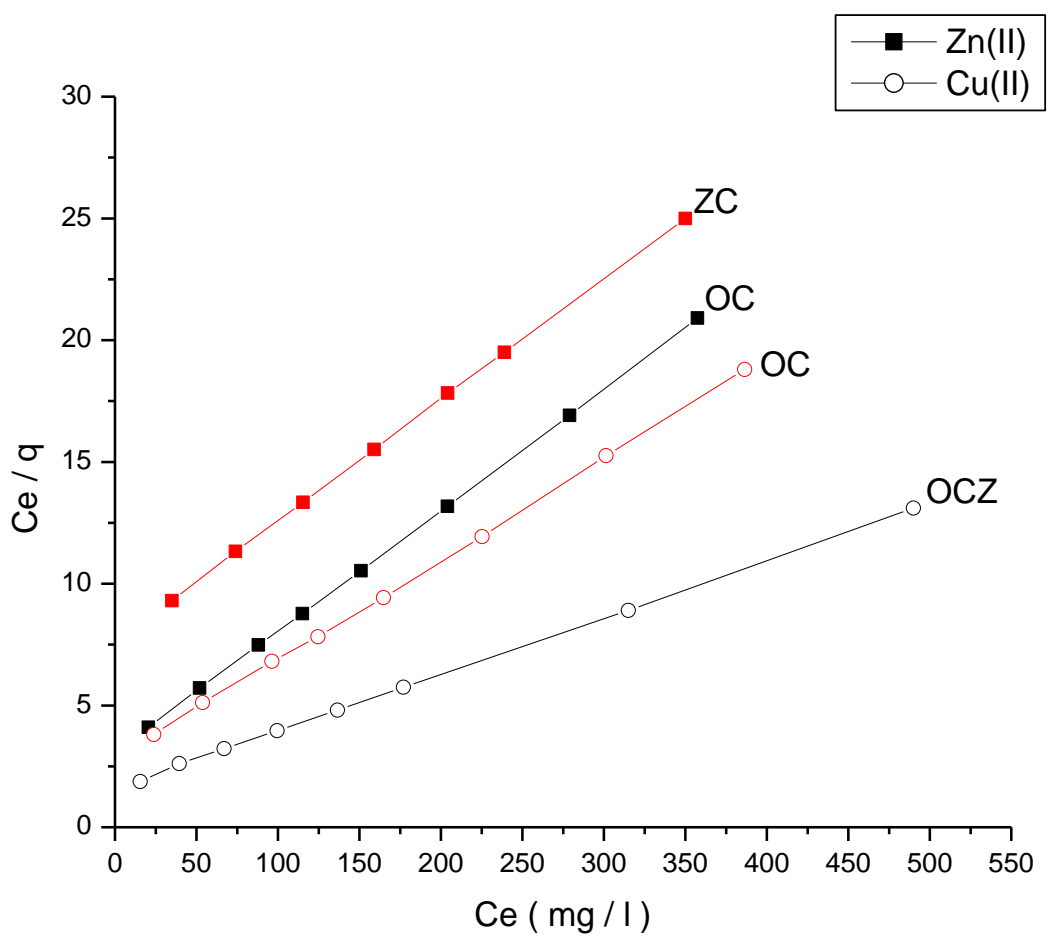

Fig.6:- Langmuir plots of $\mathrm{Cu}$ (II) and $\mathrm{Zn}$ (II) ions on some selected carbons

Table.2:- Langmuir constants for the adsorption of $\mathrm{Cu}$ (II) and Zn (II) at 298K.

\begin{tabular}{|c|c|c|c|c|c|c|c|c|}
\hline \multirow{2}{*}{ 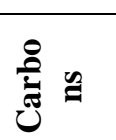 } & \multicolumn{2}{|c|}{$\begin{array}{c}\mathbf{Q}_{\mathbf{0}} \\
\left(\mathbf{m g ~ g}^{-1}\right)\end{array}$} & \multicolumn{2}{|c|}{$\begin{array}{c}\mathbf{b} \\
\left(\mathbf{L} \mathbf{~ m g}^{-1}\right)\end{array}$} & \multicolumn{2}{|c|}{$\mathbf{R}_{\mathbf{L}}$} & \multicolumn{2}{|c|}{$\overline{\mathbf{R}^{2}}$} \\
\hline & $\mathbf{C u}(\square)$ & $\mathbf{Z n}(\square)$ & $\mathbf{C u}(\square)$ & $\mathbf{Z n}(\square)$ & $\mathbf{C u}(\square)$ & $\mathbf{Z n}(\square)$ & $\mathbf{C u}(\square)$ & $\mathbf{Z n}(\square)$ \\
\hline PC & 37.4 & 25.2 & 0.057 & 0.050 & .0372 & 0.422 & 0.990 & 0.991 \\
\hline $\mathbf{Z C}$ & 26.6 & 20.1 & 0.0067 & 0.0065 & 0.2504 & 0.2537 & 0.992 & 0.989 \\
\hline OC & 24.14 & 20.08 & 0.0143 & 0.0163 & 0.1346 & 0.1199 & 0.987 & 0.990 \\
\hline $\mathrm{OCZ}$ & 42.6 & 37.4 & 0.015 & 0.013 & 0.132 & 0.1404 & 0.99 & 0.988 \\
\hline
\end{tabular}

The thermodynamic parameters $\Delta \mathrm{G}^{\mathrm{o}}, \Delta \mathrm{S}^{\mathrm{o}}$ and $\Delta \mathrm{H}^{\circ}$ for the adsorption of $\mathrm{Cu}$ (II) and $\mathrm{Zn}$ (II) by OC and OCZ carbons were calculated using the equations:

$$
\begin{array}{r}
\Delta \mathrm{G}^{0}=-\mathrm{RT} \ln \mathrm{K}_{\mathrm{a}} \\
\ln \left(\frac{\mathrm{K}_{a 2}}{K_{a 1}}\right)=-\frac{\Delta \mathrm{H}^{0}}{\mathrm{R}}\left(\frac{1}{\mathrm{~T} 2}-\frac{1}{\mathrm{~T} 1}\right) . \\
\Delta \mathrm{S}^{0}=\frac{\Delta \mathrm{H}^{0}-\Delta \mathrm{G}^{0}}{\mathrm{~T}} \ldots \ldots . .
\end{array}
$$

The equilibrium constant $\mathrm{K}_{\mathrm{a}}$ of the adsorption process which is equal to the product $\mathrm{Q}_{0} \mathrm{~b}$ was measured for each metal ion at an additional temperature namely $315 \mathrm{~K}$. The values of $\mathrm{K}_{\mathrm{a}}$ at $298 \mathrm{~K}$ and $315 \mathrm{~K}$ were used to calculate the enthalpy change " $\Delta \mathrm{H}^{\mathrm{o}}$. The calculated thermodynamic parameters for the adsorption by $\mathrm{Cu}$ (II) and $\mathrm{Zn}$ (II)by both adsorbents are summarized in Table 3. The small negative values of $\Delta \mathrm{H}^{0}$ indicate the exothermic nature of the adsorption process, which may involve weak forces of attraction. Further positive values of $\Delta \mathrm{S}^{\mathrm{o}}$ suggest the increase randomness at the solid solution interface and the affinity of the two carbons for the uptake of the two metal ions. The negative values of the free energy change $\left(\Delta G^{\circ}\right)$ confirm the spontaneous nature of adsorption.

The relatively lower value of $\Delta \mathrm{G}^{\circ}$ obtained for $\mathrm{OCZ}$ carbon indicate that $\mathrm{Cu}$ (II) and $\mathrm{Zn}$ (II) are better adsorbed on its surface than those adsorbed on OC carbons. 
Table.3: Thermodynamic parameters for the adsorption of $\mathrm{Cu}(\square)$ and $\mathrm{Zn}(\square)$ on $\mathrm{OC}$ and $\mathrm{OCZ}$ carbons.

\begin{tabular}{|c|c|c|c|c|c|c|c|c|c|}
\hline \multirow{2}{*}{ ঠิ } & \multirow[t]{2}{*}{$\begin{array}{c}\text { Temp. } \\
\text { (K) }\end{array}$} & \multicolumn{2}{|c|}{$\mathbf{K}_{\mathbf{a}}$} & \multicolumn{2}{|c|}{$\begin{array}{c}(-) \Delta \mathbf{G}^{\mathbf{0}} \\
\left(\mathbf{K J ~ m o l e}^{-1}\right)\end{array}$} & \multicolumn{2}{|c|}{$\begin{array}{c}\Delta \mathrm{S}^{0} \\
\left(\mathbf{J} \mathbf{~ m o l e}^{-1} \mathbf{K}^{-1}\right)\end{array}$} & \multicolumn{2}{|c|}{$\begin{array}{c}(-) \Delta \mathrm{H}^{\mathrm{o}} \\
\left(\mathbf{K J} \mathbf{m o l e}^{-\mathbf{1}}\right)\end{array}$} \\
\hline & & $\mathbf{C u}(\square)$ & $\mathbf{Z n}(\square)$ & $\mathbf{C u}(\square)$ & $\mathbf{Z n}(\square)$ & $\mathbf{C u}(\square)$ & $\mathbf{Z n}(\square)$ & $\mathbf{C u}(\square)$ & $\mathbf{Z n}(\square$ \\
\hline \multirow{2}{*}{ OC } & 298 & 0.345 & 0.326 & 7.65 & 7.59 & 15.48 & 20.59 & \multirow{2}{*}{3.03} & \multirow{2}{*}{1.46} \\
\hline & 315 & 0.323 & 0.317 & 7.91 & 7.94 & 15.49 & 20.58 & & \\
\hline \multirow{2}{*}{ OCZ } & 298 & 0.623 & 0.509 & 9.11 & 8.69 & 12.24 & 8.57 & \multirow{2}{*}{5.47} & \multirow{2}{*}{6.13} \\
\hline & 315 & 0.553 & 0.446 & 9.32 & 8.83 & 12.20 & 8.58 & & \\
\hline
\end{tabular}

\section{Conclusions:-}

The results show that phosphoric acid and zinc chloride activated carbons derived from date stone char are an effective and low cost adsorbent for the removal of copper and zinc ions from their aqueous solutions. The order of adsorption of the two metal ions on the tested carbons under the same conditions is $\mathrm{Cu}$ (II) $>\mathrm{Zn}$ (II). The data obtained from adsorption isotherms are well described by Langmuir model. The surface chemical nature of the activated carbons was found to play the major role to inflict the highest impact on $\mathrm{Cu}$ (II) and $\mathrm{Zn}$ (II) ions removal. Loading commercial activated carbon with $10 \mathrm{wt}$. \% hydrous zirconium oxide led to decrease both a surface area and porosity and enhance to a great extent the removal of $\mathrm{Cu}$ (II) and $\mathrm{Zn}$ (II). The negative values of $\Delta \mathrm{H}^{\mathrm{o}}$ confirm the exothermic nature of adsorption. $\mathrm{Cu}$ (II) and $\mathrm{Zn}$ (II) are better adsorbed on OCZ carbon than on OC one.

\section{References:-}

1. C. Namasivayam, K. Ranganthan, Wat. Res., 29(7), (1995) 1737-1744

2. T.K. Benjamin, K.F. Gergova, N.V. Petrov, Minkova, J. Chem. Tech. Biotechnol. 60(1994)177-182

3. B.E. Reed, S. Arunachalam, B.Thomas, Enviro.Progress. 13(1994)60-64

4. E. Demirbas, M. Kobya, S. Öncel, S. Şencan, Bioresour, Technol. 84(2002) 291-293

5. M. Sitting, Handbook of Toxic and Hazardous Chemicals, Noyes Publications, Park Ridge, NJ, 1981.

6. J.W. Patterson, Industrial Wastewater Treatment Technology, $2^{\text {nd }}$ Ed., Butterworth-Heinemann, London, 1985

7. A.sohail, S.I. Ali, N.A. Khan, R.A.K. Rao, Environ. J. Pollut. Contr. 2(1999)27-31.

8. H.A. Elliot, C.P. Huang, Water Res. 15(1984)849-855

9. K.P. Shubha, C. Raji, T.S. Anirudhan, Water Res. 35(2001)300-310

10. S. Deng, R. Bai, J.P. Chen, J. Colloidal Interface Sci. 260 (2003)265-272

11. G.N. Manju, K.A. Krishnan, V.P. Vinod, T.S. Anirudhan, J. Hazard. Mater. B91 (2002) 221-238

12. C.O. Ania, J.B. Parra, J.J. Pis, Fuel Process. Technol. 77-78 (2002) 337

13. N. Klimenko, M. Winter-Nielsen, S. Smolin, L. Nevynna, J. Sydorenko, Water Res. 36(2002)5132

14. A.M. Youssef, M.R. Mostafa, E.M. Dorgham, Bull. Soc. Chim. Fr., (1989)741

15. A.M. Youssef, A.M. El-wakil, E.A. El-Sharkawy, A.B. Farag, Kh. Tollan, Adsorp. Sci. Technol. 13(1996) 115

16. V. Strelko, D.J. Malik, J. Colloid Interface Sci. 250(2002) 213

17. K. Kadirvelu, C. Namasivayam, Adv. Environ. Res. 7(2003) 471

18. B. Yu, Y. Zhang, A. Shukla, S.S. Shukla, K.L. Dorris, J. Hazard. Mater. 80(2000)33

19. K.K. Wong, C.K. Lee, K.S. low, M.J. Haron, Chemosphere 50 (2003) 23

20. K.S. Low, C.K. Lee, A.C. Leo, Bioresour. Technol. 51(1995) 227

21. K.A. Krishnan, T.S. Anirudhan, Water SA 29, 2003, PP 147

22. K. Perisany, C. Namasivayam, Chemosphere 32 (1996) 769

23. M. Pasavento, A. Profumo, G. Alberti, F. Conti, Anal. Chim. Acta 480(2003) 171-180

24. A. Shukla, Y.-H. Zhang, P.Dubey, J.L. Margrave, S. Shukla, J hazard. Mater. B95 (2000) 137-152

25. F. Rouquerol, J. Rouquerol, K. Sing, Academic Press, 1999

26. Freeman JJ, Gimblett FGR, Sing KSW, Carbon 26 (1988) 7

27. Freeman JJ, Gimblett FGR, Sing KSW, Carbon 25 (1987) 559

28. Bradly RH, Rand B, Carbon 29(1991) 1165

29. S. Brunauer, P.H Emmett, E. Teller, Am. Chem.Soc 60 (1938)309

30. M.J. Sellez-Perez, J.M Martin-Martinez, Chem.Soc. Faraday Trans. 87(1991)1237

31. H. Yang, R. Yan, H. Chen, D.H. Lee, C. Zheng, Fuel 86 (2007) 1781-1788

32. El-Hendawy Abdel-Nasser A., Appl. Surf. Sci. 252(2005) 287-295 
33. R. Bouwman, I.L.C. Freriks, Fuel 59 (1980) 315-322

34. L.J. Bellamy, Wiley, New York, 1954

35. B. Mokili, Y. Charreire, R. Cortes, D. Lincot, Thin Solid Films 288(1996) 21-28

36. R. Silverstein, F. Webster, Wiley, New York, 1998

37. M. Signoretto, F. Pinna, G. Strukul, P. Chis, J. Catel. 167(1997)522

38. M. Le Toullec, C.J. Simmons, J.H. Simmons, J. Am. Ceram.Soc. 71(1988)219

39. D. Saekar, D. Mohapatra, S. Ray, S. Bhathacharyya, S. Adak, N.Mitra, Ceram.Ins. 33(2007)1275

40. I. Langmuir, J. Am. Chem. Soc. 40(1918)1361

41. F. Rozada, L. F. Calvo, A. I. Garcia, J.Martin-Villacorta. M.Otero, Bioresour. Technol. 87 (2003) 221 